\title{
Targeted next generation sequencing of endoscopic ultrasound acquired cytology from ampullary and pancreatic adenocarcinoma has the potential to aid patient stratification for optimal therapy selection
}

\author{
Ferga C. Gleeson ${ }^{1}$, Sarah E. Kerr², Benjamin R. Kipp ${ }^{2}$, Jesse S. Voss², Douglas M. \\ Minot $^{2}$, Zheng Jin Tu ${ }^{3}$, Michael R. Henry ${ }^{2}$, Rondell P. Graham², George Vasmatzis ${ }^{4}$, \\ John C. Cheville ${ }^{4}$, Konstantinos N. Lazaridis ${ }^{1,4}$, Michael J. Levy ${ }^{1}$ \\ ${ }^{1}$ Division of Gastroenterology \& Hepatology, Mayo Clinic Rochester, MN, USA \\ ${ }^{2}$ Department of Laboratory Medicine \& Pathology, Mayo Clinic Rochester, MN, USA \\ ${ }^{3}$ Division of Biomedical Statics \& Informatics, Department of Health Sciences Research, Mayo Clinic Rochester, MN, USA \\ ${ }^{4}$ Center for Individualized Medicine, Mayo Clinic, Rochester, MN, USA \\ Correspondence to: Ferga C. Gleeson, email: gleeson.ferga@mayo.edu \\ Keywords: endoscopic ultrasound fine needle aspiration, pancreatic adenocarcinoma, targeted next-generation sequencing, \\ mutation concordance, personalized medicine \\ Received: April 04, $2016 \quad$ Accepted: April 24, $2016 \quad$ Published: May 18, 2016
}

\section{ABSTRACT}

Background \& Aims: Less than $10 \%$ of registered drug intervention trials for pancreatic ductal adenocarcinoma (PDAC) include a biomarker stratification strategy. The ability to identify distinct mutation subsets via endoscopic ultrasound fine needle aspiration (EUS FNA) molecular cytology could greatly aid clinical trial patient stratification and offer predictive markers. We identified chemotherapy treatment naïve ampullary adenocarcinoma and PDAC patients who underwent EUS FNA to assess multigene mutational frequency and diversity with a surgical resection concordance assessment, where available.

Methods: Following strict cytology smear screening criteria, targeted next generation sequencing (NGS) using a 160 cancer gene panel was performed.

Results: Complete sequencing was achieved in 29 patients, whereby 83 pathogenic alterations were identified in 21 genes. Cytology genotyping revealed that the majority of mutations were identified in KRAS (93\%), TP53 (72\%), SMAD4 $(31 \%)$, and GNAS (10\%). There was $100 \%$ concordance for the following pathogenic alterations: KRAS, TP53, SMAD4, KMT2D, NOTCH2, MSH2, RB1, SMARCA4, PPP2R1A, PIK3R1, SCL7A8, ATM, and FANCD2. Absolute multigene mutational concordance was $83 \%$. Incremental cytology smear mutations in GRIN2A, GATA3 and KDM6A were identified despite re-examination of raw sequence reads in the corresponding resection specimens.

Conclusions: EUS FNA cytology genotyping using a 160 cancer gene NGS panel revealed a broad spectrum of pathogenic alterations. The fidelity of cytology genotyping to that of paired surgical resection specimens suggests that EUS FNA represents a suitable surrogate and may complement the conventional stratification criteria in decision making for therapies and may guide future biomarker driven therapeutic development. 


\section{INTRODUCTION}

Conventional non-targeted chemotherapy regimens are the standard of care for patients with ampullary (AA) and pancreatic adenocarcinoma (PDAC). Yet, clinical trials frequently offer targeted agents to patients without screening for actionable pathogenic alterations. Less than $10 \%$ of registered drug intervention trials for PDAC include a biomarker stratification strategy. [1] The five most commonly mutated genes of PDAC in the Catalogue of Somatic Mutations in Cancer (COSMIC) database are KRAS (71\%), TP53 (49\%), CDKN2A (22\%), SMAD4 (20\%), and ARID1A (6\%). [1] In 2014, the National Cancer Institute (NCI) created a scientific framework for PDAC with 4 initiatives. [2] The objective of one of these initiatives was to expand PDAC research to develop new approaches that interfere with RAS oncogene dependent signaling pathways. RAS can activate several downstream effectors, including the PI3K-AKT-mTOR and the RASRAF-MEK-ERK pathways, which are involved in cell survival and proliferation.

Evolving novel therapeutic strategies include agents that not only target the tumor itself, but also the tumor microenvironment. Such unique or combined approaches include vaccine based immunotherapy, the use of stromal depleting agents, BRCA related therapies, inhibitors of autophagy, angiogenesis inhibition and $\mathrm{NOTCH}$ signaling pathway inhibitors. [3-5] Genetic signatures could be used to direct personalized PDAC treatment in the future. [6]

The ability to identify distinct mutation subsets via endoscopic ultrasound fine needle aspiration (EUS FNA) molecular cytology could greatly aid clinical trial patient stratification for optimal therapy selection and offer predictive markers. Such a development would represent a crucial step in the field of personalized medicine. It has been observed that tumors characterized by a concurrent TP53 and SMAD4 wild type status have an indolent behavior and an improved therapy response with low metastatic potential. [7, 8] However, TP53 mutant tumors accompanied by a SMAD4 wild type profile exhibit increased metastatic potential, and finally a combination of TP53 and SMAD4 mutations represent the most aggressive and widespread metastatic PDAC. Therefore, stratification of cytotoxic agent eligible patients using EUS FNA specimens to determine the multigene mutation status may be of prognostic benefit and facilitate appropriate tumor specific targeted therapy.

The aims of our translational study using a commercially available 160 gene targeted NGS comprehensive cancer panel were to determine among a cohort of patients with chemotherapy treatment naïve $\mathrm{AA}$ and PDAC the 1.) multigene mutational landscape within EUS FNA cytology smear specimens, 2.) spectrum of functional gene groupings, 3.) frequency and subtype of KRAS, TP53 and SMAD4 pathogenic alterations and
4.) multigene mutation concordance between paired EUS FNA cytology smears and surgical resection specimens.

\section{RESULTS}

\section{Clinical demographics}

Targeted NGS was achieved in 29 chemotherapy naïve patients $[65.4 \pm 13.4$ years, male gender $\mathrm{n}=19$ $(65.5 \%)]$. Three (10.3\%) patients were $<45$ years of age at the time of diagnosis. A family history $(\geq 1$ first degree relative) of PDAC was notable for $3(10.3 \%)$ patients. Smoking status at the time of FNA included never smokers $[\mathrm{n}=13(44.8 \%)]$ and ex or current smokers $[\mathrm{n}=16(55.3 \%)]$ with a 13.5 (5-20) pack year history. The Ca19-9 level at diagnosis was $88(30-260) \mathrm{U} / \mathrm{mL}[\mathrm{normal}<55 \mathrm{U} / \mathrm{mL}$ : $\mathrm{n}=17(58.6 \%)>55 \mathrm{U} / \mathrm{mL}]$. The fasting serum glucose level was 112 (96-153.5) mg/dL (normal 70-100 mg/dL), $17(62.1 \%)$ of whom had a level $>100 \mathrm{mg} / \mathrm{dL}$ at diagnosis.

\section{Tumor demographics}

The cohort was comprised of the following: PDAC [ $\mathrm{n}=21(72.4 \%) ; 20$ primary and 1 recurrent], AA $[\mathrm{n}=4(13.8 \%)]$, malignant transformation of intraductal papillary mucinous neoplasm (IPMN) [ $\mathrm{n}=3(10.3 \%)]$, and Lynch Syndrome associated PDAC [n=1 (3.4\%)]. The tumors were located within the pancreatic: head $[\mathrm{n}=19(65.5 \%)]$, body $[\mathrm{n}=5(17.2 \%)]$, ampulla $[\mathrm{n}=4$ $(13.8 \%)]$, and complete gland infiltration $[\mathrm{n}=1(3.4 \%)]$. The median tumor size at EUS was $3 \mathrm{~cm}(2.5-4.1)$. The spectrum of subsequent surgical intervention included the following: pancreaticoduodenectomy $[\mathrm{n}=20(69 \%)]$, distal pancreatectomy $[\mathrm{n}=5(17.2 \%)]$, total pancreatectomy $[\mathrm{n}=3$ $(10.3 \%)]$, and a completion pancreatectomy for a patient with recurrent disease $[n=1(3.4 \%)]$.

\section{Disease recurrence and mortality}

Disease recurrence developed in $17(58.6 \%)$ patients at 13 (7.7-21.5) months following EUS FNA. The initial site of tumor recurrence was liver $[\mathrm{n}=6(35.3 \%)]$, peritoneum [ $\mathrm{n}=5(29.4 \%)]$, lung $[\mathrm{n}=2(11.8 \%)]$, malignant ascites $[\mathrm{n}=2(11.8 \%)]$, a new primary $[\mathrm{n}=1(5.9 \%)]$, and a cutaneous chest drain site $[\mathrm{n}=1(5.9 \%)]$. Twenty $(68.9 \%)$ patients died at a median of 17.8 (10.9-32.6) months. Overall follow up from the time of EUS FNA to mortality or to the end of the study was 22.9 (10.9-42.6) months.

\section{Cytology genotyping using a commercially available comprehensive cancer panel}

Targeted NGS sequencing revealed that 83 pathogenic alterations were identified in 21 genes. (Supplementary Table 1) Patients harbored a median of 2 (2-3.5) pathogenic alterations per tumor. Twenty-seven 
Table 1: EUS FNA pathogenic alteration spectrum in 29 patients

\begin{tabular}{|c|c|c|c|}
\hline & Gene & Number of patients & Mutation frequency \\
\hline 1 & KRAS & 27 & $93.1 \%$ \\
\hline 2 & TP53 & 21 & $72.4 \%$ \\
\hline 3 & SMAD4 & $9 *$ & $31 \%$ \\
\hline 4 & GNAS & 3 & $10.3 \%$ \\
\hline 5 & ARIDla & $2 * *$ & $6.9 \%$ \\
\hline 6 & NOTCH2 & 2 & $6.9 \%$ \\
\hline 7 & KMT2D & 2 & $6.9 \%$ \\
\hline 8 & KDM6A & 2 & $6.9 \%$ \\
\hline 9 & HNF1A & 1 & $3.5 \%$ \\
\hline 10 & CARD11 & 1 & $3.5 \%$ \\
\hline 11 & SMARCA4 & 1 & $3.5 \%$ \\
\hline 12 & PPP2R1A & 1 & $3.5 \%$ \\
\hline 13 & PIK3R1 & 1 & $3.5 \%$ \\
\hline 14 & SCL7A8 & 1 & $3.5 \%$ \\
\hline 15 & MSH2 & 1 & $3.5 \%$ \\
\hline 16 & RB1 & 1 & $3.5 \%$ \\
\hline 17 & ATM & 1 & $3.5 \%$ \\
\hline 18 & FANCD2 & 1 & $3.5 \%$ \\
\hline 19 & FBXW7 & 1 & $3.5 \%$ \\
\hline 20 & GATA3 & 1 & $3.5 \%$ \\
\hline 21 & GRINDA & 1 & $3.5 \%$ \\
\hline
\end{tabular}

Of 29 patients: $* 1$ patient had 2 SMAD4 alterations: $* * 1$ patient had 2 ARID1A alterations

(93.1\%), $13(44.8 \%)$ and $6(20.7 \%)$ patients harbored $\geq 2$, $\geq 3$ and $\geq 4$ pathogenic alterations per tumor, respectively. Genotyping revealed that the majority of mutations were identified in KRAS (93.1\%), TP53 (72.4\%), SMAD4 (31\%), and GNAS (10.3\%). (Table 1) All patients with GNAS mutations had concurrent KRAS and TP53 comutations. No somatic P16 mutations were identified. Based on currently available chemotherapeutic agents, no "actionable" or "druggable" mutations were identified in $B R A F, P I K 3 C A, B R C A, P A L B 2, E R B B 1, M E T, F G F R 1$, or EGFR.

\section{Characterization of the KRAS mutational profile}

The observed KRAS mutations were composed of alterations in codons 12,13 and 61 in $85.2 \%, 3.7 \%$ and $11.1 \%$, respectively. The most frequently identified genotypes were Gly12Val (33\%) and Gly12Asp (33\%) (Figure 1). Alterations in codons 13 and 61 were only identified in either current or former smokers. Overall survival for patients with a KRAS mutation was 24.2 (13.844.6) months. Neither Gly12Val (HR $=0.6292 ; 95 \%$ CI 0.2505 to $1.5807 ; \mathrm{p}=0.36)$ or Gly12Asp ( $\mathrm{HR}=0.9956$; $95 \%$ CI 0.3829 to 2.5887 ; $=0.99$ ) status was associated with disease related mortality. Two $K R A S$ wild-type (WT) patients harbored mutations in TP53 and FBXW7, respectively.

\section{Characterization of the TP53 mutational profile}

Twenty-one patients harbored 20 TP53 mutations including 15 missense mutations, 2 nonsense mutations, 1 splice site mutation, 1 in-frame deletion and 1 single base pair duplication resulting in a premature stop codon (Supplementary Table 2). TP53 was the second most frequently identified pathogenic alteration in patients, 19 $(90.5 \%)$ and $5(23.8 \%)$ of whom had either a KRAS or SMAD4 co mutation. 
Table 2: SMAD4 mutant population clinical demographics and pathogenic alteration status

\begin{tabular}{|c|c|c|c|}
\hline & $\begin{array}{c}\text { SMAD } 4 \\
\text { mutant } \\
\mathrm{N}=9\end{array}$ & $\begin{array}{c}\text { SMAD } 4 \\
\text { WT } \\
\mathbf{N}=\mathbf{2 0}\end{array}$ & P value \\
\hline Age (years) & $63.1 \pm 14.2$ & $66.2 \pm 13.3$ & 0.574 \\
\hline Gender (male) & $6(66.7 \%)$ & $13(65 \%)$ & 0.9 \\
\hline $\begin{array}{l}\text { Positive Family History ( } 1^{\text {st }} \text { degree } \\
\text { relative) }\end{array}$ & $1(11.1 \%)$ & $2(10 \%)$ & 0.9 \\
\hline Current Smoker & $6(66.7 \%)$ & $10(50 \%)$ & 0.4543 \\
\hline Ca $19-9(\mathrm{U} / \mathrm{mL})$ & $689 \pm 1,398.7$ & $146.7 \pm 159.6$ & 0.0915 \\
\hline Fasting glucose (mg/dL) & $139.3 \pm 70.1$ & $124.2 \pm 36.5$ & 0.4486 \\
\hline Elevated glucose $(>100 \mathrm{mg} / \mathrm{dL})$ & $8(88.9 \%)$ & $9(45 \%)$ & 0.0432 \\
\hline Location (head) & $5(55.6 \%)$ & $14(70 \%)$ & 0.6749 \\
\hline Size $(\mathrm{cm})$ & $4.5 \pm 3.2$ & $3.3 \pm 1.7$ & 0.1953 \\
\hline $\mathrm{TNM} \geq \mathrm{T} 3 \mathrm{~N} 0$ & $9(100 \%)$ & $13(65 \%)$ & 0.0661 \\
\hline Stage Grouping $\geq 2 b$ & $6(66.7 \%)$ & $14(70 \%)$ & 0.9 \\
\hline Perineural Invasion & $6(66.7 \%)$ & $7(35 \%)$ & 0.2256 \\
\hline R0 Resection Status & $9(100 \%)$ & $17(85 \%)$ & 0.5320 \\
\hline Disease Recurrence & $7(77.8 \%)$ & $10(50 \%)$ & 0.2341 \\
\hline Mortality & $7(77.8 \%)$ & $13(65 \%)$ & 0.6749 \\
\hline Time to Mortality (months) & $18.3 \pm 8.5$ & $20.3 \pm 14.7$ & 0.7082 \\
\hline Progression Free Survival & $2(2 \%)$ & $6(30 \%)$ & 0.9 \\
\hline KRAS mutant status & $9(100 \%)$ & $17(85 \%)$ & 0.5320 \\
\hline P53 mutant status & $5(55.6 \%)$ & $17(85 \%)$ & 0.1581 \\
\hline KDM6A mutant status & $2(22.2 \%)$ & $0(0 \%)$ & 0.0887 \\
\hline$\geq 2$ pathogenic alterations/tumor & $9(100 \%)$ & $17(85 \%)$ & 0.5320 \\
\hline$\geq 3$ pathogenic alterations/tumor & $8(88.9 \%)$ & $4(20 \%)$ & 0.0009 \\
\hline$\geq 4$ pathogenic alterations/tumor & $3(33.3 \%)$ & $3(15 \%)$ & 0.3391 \\
\hline
\end{tabular}

\section{Characterization of the SMAD 4 mutational profile}

Ten SMAD 4 pathogenic alterations, the third most common alteration in the cohort, were observed in $9(31 \%)$ patients, but in no patient with AA. SMAD 4 genotyping revealed a heterogeneous group of pathogenic alterations to include: p. Arg361Cys, p. Trp524Cys, p. Gln256Ter, p. Ala406Val x 2, p. His530ThrfsTer47, p. Arg135Ter, p. Asp351del, p. Asp351GlyfsTer27, and p. Tyr114IlefsTer7, respectively. There were no clinical demographic differences between SMAD 4 mutant and WT patients to include: age, gender, first degree relative with PDAC, smoking status, fasting glucose status, baseline Ca19-9 level, tumor location, size or stage, disease recurrence or mortality (Table 2). All patients had concurrent KRAS mutations.

\section{Multigene mutational concordance with paired surgical pathology specimens}

In parallel with the cytology smear specimens, matched site surgical pathology specimens of 18 patients, who were selected as they had sufficient material for a multigene mutation concordance evaluation $[64.6 \pm 12.0$ years; male gender $\mathrm{n}=11$ (61.1\%); Ca19-9 level: 59 (30186) $\mathrm{U} / \mathrm{mL}$; fasting glucose $(\mathrm{mg} / \mathrm{dL}): 112.5$ (96-143)] also underwent targeted NGS with the Qiagen ${ }^{\mathrm{TM}}$ Human Comprehensive Cancer GeneRead DNAseq Targeted Array V2. 
Paired cytology NGS with matched surgical pathology NGS patients revealed 56 and 50 pathogenic alterations, respectively, in 19 and 16 genes. Five $(27.8 \%)$ patients had $\geq 4$ pathogenic alterations identified per tumor. KRAS (94.4\%), TP53 (66.7\%) and SMAD 4 (38.9\%) were the most frequently identified pathogenic alterations. Fifteen of $18(83.3 \%)$ paired patients had absolute multigene mutational concordance (Table $3)$. There was $100 \%$ concordance for the following individual pathogenic alterations: KRAS, TP53, SMAD4, KMT2D, NOTCH2, MSH2, RB1, SMARCA4, PPP2R1A, PIK3R1, SCL7A8, ATM, and FANCD2. Mutations in GRIN2A (p. Val1197Met) (allele frequency $=14 \%$ ), GATA3 (p. Ala102Thr) (allele frequency $=6 \%$ ), GNAS (p.Gly282Ser) (allele frequency $=5 \%$ ) and $K D M 6 A(\mathrm{p}$. Gln524Ter) (allele frequency $=7 \%$ ) were only identified within the EUS FNA cytology specimens from three patients despite careful re-examination of the of the raw sequence reads in the resection specimens (Figure 2). The estimated tumor $\%$ in these 2 patients for FFPE versus cytology specimens were similar (70\% vs. $70 \%$ and $70 \%$ vs. $30 \%$, respectively). Overall, the average mutant allele frequencies in paired FFPE versus cytology samples with concordant mutations were $35 \%$ versus $34 \%$, also suggesting similar tumor percentage between FFPE and cytology samples.

\section{DISCUSSION}

Pancreatic ductal and ampullary adenocarcinomas are biologically heterogeneous tumors. Detailed global genomic analyses have identified that there are 12 core signaling pathways and 16 genes significantly genetically altered in the majority of PDAC patients. [10-11] We have previously reported a 50 gene mutation assessment of a spectrum of other primary, locally advanced and metastatic diseases using EUS FNA cytology specimens. [9, 12-16] Our newly presented data represent a multigene mutation assessment of 160 cancer associated genes using targeted NGS. This unique assessment further exemplifies the collective genetic diversity of PDAC - AA and may be used to identify specific molecular patient cohorts most likely to benefit from agents designed to target specific pathways or genomic features. [17]

The ability to apply targeted NGS to routine EUS FNA cytology offers tremendous promise for such an endeavor in an evolving era of individualized medicine. We have observed a broad spectrum of pathogenic alterations in 21 genes, whereby $93 \%$ of patients had $\geq 2$ pathogenic alterations per tumor. This further highlights the clear need for customized combination therapy with the goal of enhancing therapeutic response and patient outcome.

The performance of KRAS mutation analysis in EUS FNA pancreas mass specimens from a variety of molecular techniques is well documented. [18-23] However, we report that an EUS FNA molecular cytology assessment with targeted NGS has the ability to identify and dissect KRAS mutation subtypes as part of a multigene mutation analysis. Furthermore, EUS FNA identified that $31 \%$ of our cohort harbored a SMAD4 mutation and they were more likely to harbor

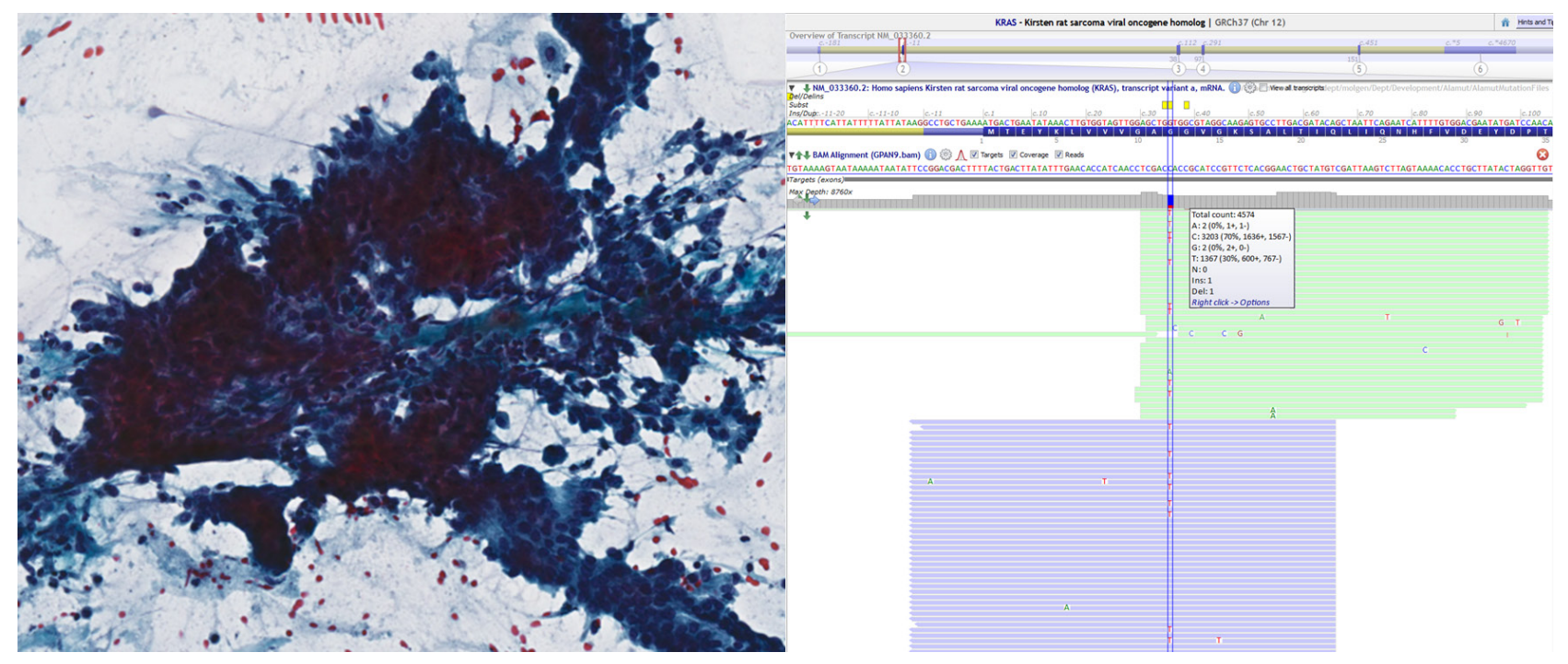

Figure 1: Pap-stained cytology slide (left) from pancreatic adenocarcinoma. The sheet of cells shows loss of polarity, crowding and overlapping nuclei. Representative sequencing results (right) in Alamut showing KRAS c.35G $>$ A, p. Gly12Asp missense mutation in $30 \%$ of alleles. Note that the reverse strand was sequenced suggesting a $\mathrm{C}>\mathrm{T}$ mutation in the figure. 
Table 3: Paired concordance assessment of EUS FNA cytology to matched surgical pathology

\begin{tabular}{|c|c|c|c|c|c|}
\hline Patient & $\begin{array}{c}\text { primary } \\
\text { pathology }\end{array}$ & stage grouping & Cytology & surgical pathology & Concordance \\
\hline 1 & PDAC & $\mathrm{Ib}$ & KRAS, SMAD4, ATM & KRAS, SMAD4, ATM & $100 \%$ \\
\hline 2 & PDAC & IIa & KRAS, SMAD4 & KRAS, SMAD4 & $100 \%$ \\
\hline 3 & PDAC & $\mathrm{IIb}$ & TP53, SMAD4 & TP53, SMAD4 & $100 \%$ \\
\hline 4 & PDAC & $\mathrm{IIb}$ & KRAS, SMAD4 & KRAS, SMAD4 & $100 \%$ \\
\hline 5 & IPMN & IIa & TP53, KRAS, SMAD4 & TP53, KRAS, SMAD4 & $100 \%$ \\
\hline 6 & PDAC & $\mathrm{IIb}$ & TP53, KRAS & TP53, KRAS & $100 \%$ \\
\hline 7 & PDAC & Ia & TP53, KRAS & TP53, KRAS & $100 \%$ \\
\hline 8 & PDAC & $\mathrm{IIb}$ & TP53, KRAS & TP53, KRAS & $100 \%$ \\
\hline 9 & PDAC & $\mathrm{IIb}$ & $\begin{array}{c}\text { TP53, KRAS, } \\
\text { SMARCA4, PPP2R1A }\end{array}$ & $\begin{array}{c}\text { TP53, KRAS, } \\
\text { SMARCA4, PPP2R1A }\end{array}$ & $100 \%$ \\
\hline 10 & PDAC & $\mathrm{IIb}$ & $\begin{array}{l}\text { TP53, KRAS, } \\
\text { SCL7A8 }\end{array}$ & $\begin{array}{l}\text { TP53, KRAS, } \\
\text { SCL7A8 }\end{array}$ & $100 \%$ \\
\hline 11 & PDAC & $\mathrm{IIb}$ & TP53, KRAS & TP53, KRAS & $100 \%$ \\
\hline 12 & PDAC & $\mathrm{IIb}$ & $\begin{array}{l}\text { TP53, KRAS, GNAS, } \\
\text { CARD11, RB1 }\end{array}$ & $\begin{array}{l}\text { TP53, KRAS, } \\
\text { CARD11, RB1 }\end{array}$ & $80 \%$ \\
\hline 13 & $\begin{array}{l}\text { Lynch associated } \\
\text { PDAC }\end{array}$ & Ia & $\begin{array}{c}\text { TP53, KRAS, GNAS, } \\
\text { NOTCH2, MSH2, } \\
\text { ARID1a }\end{array}$ & $\begin{array}{c}\text { TP53, KRAS, GNAS, } \\
\text { NOTCH2, MSH2, } \\
\text { ARID1a }\end{array}$ & $100 \%$ \\
\hline 14 & PDAC & IV & $\begin{array}{c}\text { TP53, KRAS, } \\
\text { SMAD4, KDM6A, } \\
\text { ARID1a (x 2), } \\
\text { PIK3R1, GATA3 }\end{array}$ & $\begin{array}{c}\text { TP53, KRAS, } \\
\text { SMAD4, PIK3R1 }\end{array}$ & $57 \%$ \\
\hline 15 & PDAC & IIa & $\begin{array}{l}\text { KRAS, SMAD4, } \\
\text { KMT2D, FANCD2 }\end{array}$ & $\begin{array}{l}\text { KRAS, SMAD4, } \\
\text { KMT2D, FANCD2 }\end{array}$ & $100 \%$ \\
\hline 16 & PDAC & $\mathrm{IIb}$ & KRAS, NOTCH2 & KRAS, NOTCH2 & $100 \%$ \\
\hline 17 & AA & IIa & KRAS, GRINDA & KRAS & $50 \%$ \\
\hline 18 & PDAC & III & TP53, KRAS, SMAD4 & TP53, KRAS, SMAD4 & $100 \%$ \\
\hline
\end{tabular}

additional pathogenic alterations when compared to their WT counterparts. We did not observe currently "druggable" mutations within the evaluated cohort as the following were of wild type status: BRAF, PIK3CA, BRCA, PALB2, ERBB1, MET, FGFR1, and EGFR. Nevertheless, our discoveries could be applied to prospective clinical trials and aid a combined phenotypic-genotypic approach to facilitate the development of precision medicine.

These are the first data from a commercial 160 cancer gene panel demonstrating that EUS FNA cytology specimens provide an ideal surrogate to surgical specimens for detecting pathogenic alterations associated with PDAC and AA. This information is key given the narrow cohort that would undergo a surgical biopsy and the necessity for pre-operative delivery of personalized tumor specific care. Interestingly, we identified that the observed cytology mutational spectrum was broader than that of the corresponding surgical pathology specimens. Mutations in GRIN2A, GATA3 and KDM6A which have been identified in melanoma, breast cancer and recently identified as a candidate driver of pancreatic carcinogenesis, respectively, were only identified within the EUS FNA cytology smear specimens. [24-26] The absolute multigene mutational profile concordance was $83 \%$. This may in part be a reflection upon the tumor microenvironment which is otherwise referred to as desmoplasia or stroma and is comprised of immune cells, macrophages, fibroblasts, myofibroblasts, vascular components and a dense extracellular matrix. [27] Up to $90 \%$ of a PDAC tumor mass is composed of the aforementioned desmoplastic stroma which can make 
the evaluation of tumor cells within a histopathologic specimen challenging. [28] Cytology FNA specimens have the potential to capture more mutations due to the natural concentration of tumor cells in such specimens, as the less cohesive tumor cells may be extracted while the residual dense stromal matrix is excluded. Furthermore, intratumoral heterogeneity represents a variation in tumor behavior between varying sites within the same tumor. We speculate that tumor heterogeneity may have been responsible for the additional mutations detected in 3 cytology specimens. This morphological variation between regions within a tumor has long been familiar to histopathologists but is now gaining increased recognition among clinicians as it may partially account for an impaired treatment response. EUS FNA has the potential to sample cells from a greater number of regions within a tumor than a single FFPE section due to the multiple FNA passes obtained from the tumor in question during an EUS procedure. All of these procedural and sample preparation factors favor EUS FNA as a more sensitive technique for detecting molecular alterations within desmoplastic tumors.

This is a small but fruitful study of archived EUS FNA specimens to illustrate tumor genetic diversity, but if completed on a larger scale could define subgroups with distinct biologic behaviors and even compare and contrast individuals with pancreas adenocarcinoma and separately those with ampullary adenocarcinoma. In an attempt to overcome molecular cytology adequacy challenges, we adhered to strict cytology and FFPE slide screening protocols to qualify samples likely to have a successful NGS. By so doing, it reduced the numbers of patients available to us for evaluation. This therefore prompts the future refinement not only of rapid on site evaluation (ROSE) for cytology adequacy parameters but also corresponding metrics for ROSE molecular adequacy assessments. If such "molecular adequacy" parameters were determined within the procedure room, it could ensure that superior material is obtained for molecular testing than is currently the standard of care for diagnostic purposes only. From a very practical perspective, the turnaround time for molecular diagnostic testing from biopsy procurement to delivery of test results needs to be minimized, if it is to become useful and relevant in a clinical setting. Cancer gene panels are limited to mutation assessment, which although very generous at 160 genes for this particular study, commercial panels most often do

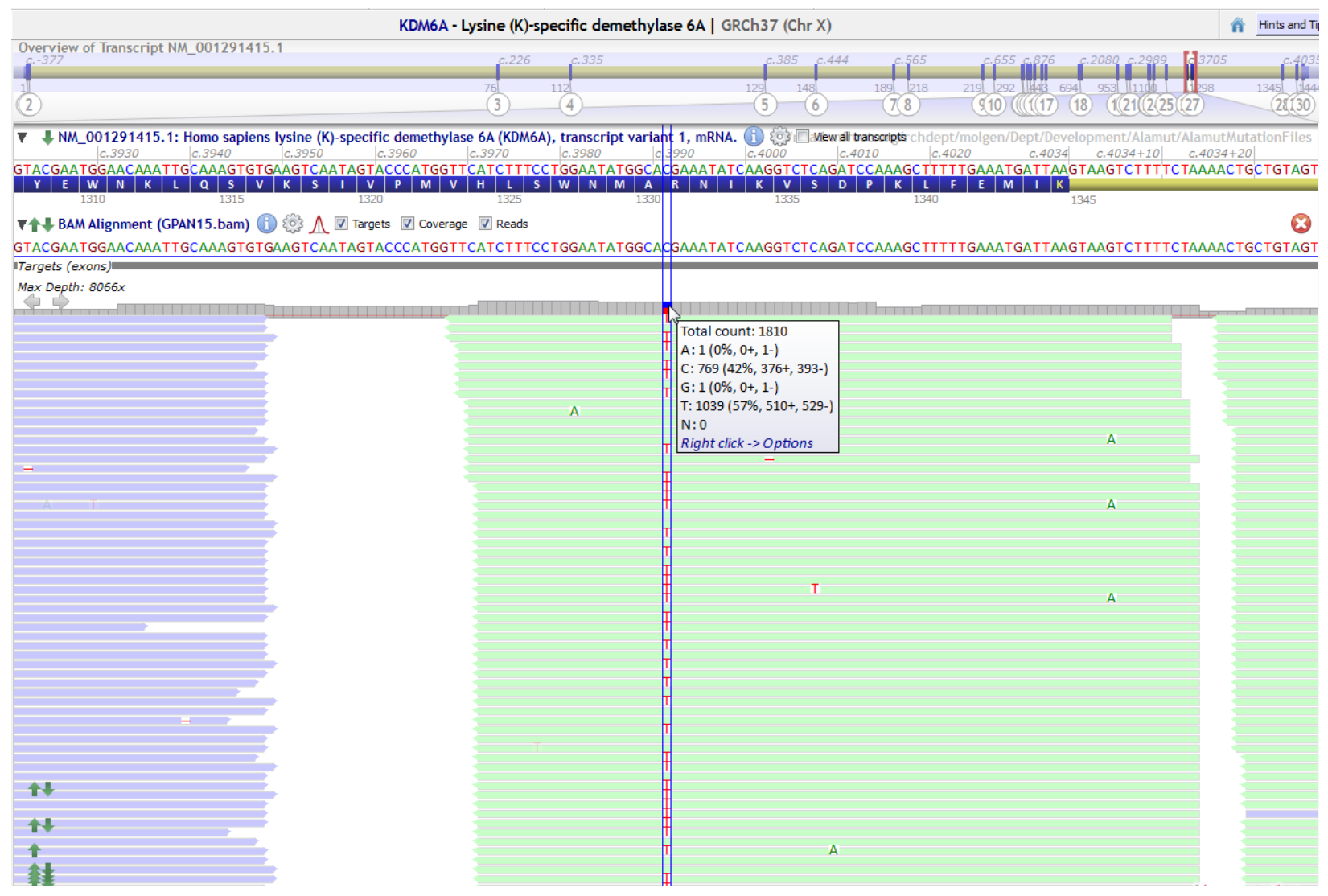

Figure 2: Example of a sequencing data in Alamut displaying nonsense mutation (c.3991C $>$ T, p. Arg1331X) in KDM6A with an allele frequency of $57 \%$. 
not include assessments of chromosomal translocations and copy number variants, which would certainly broaden our understanding of an individual tumor's biologic behavior.

In summary, our study has demonstrated the ability to use a moderate-large targeted NGS cancer gene panel in cytology smear specimens obtained via EUS from PDAC and AA patients as a suitable surrogate for surgically acquired specimens. Such cytology specimens may in fact deliver incremental genetic diversity information. Stratification of patients and targeting of therapy as per $\mathrm{NCI}$ initiatives is essential to further expand the developing field of personalized medicine in a truly heterogeneous patient population. The combination of a molecular prognostic and targeted therapy sensitivity grouping may complement the conventional clinicopathologic risk stratification criteria in decision making for clinically based or clinical trial neoadjuvant and adjuvant therapies and guide biomarker driven therapeutic development.

\section{MATERIALS AND METHODS}

\section{Patient population}

Following Mayo Clinic IRB approval, primary malignancy DNA was extracted from 47 chemotherapy naïve patients from archived (2009-2013) molecular cytology single slide smear specimens. The surgical stage pathology grouping was as follows: Ia (7\%), Ib (10\%), IIa (14\%), IIb (62\%), III (4\%) and IV (3\%). Perineural invasion was identified in $13(44.8 \%)$ patients and an R0 status was established in $26(89.7 \%)$ patients. All selected slides had $\geq 20 \%$ tumor cells in a background of benign nucleated cells. The use of strict screening criteria allowed the exclusion of 13 patients with insufficient DNA quantity $(<5 \mathrm{ng} / \mu \mathrm{l}) .{ }^{(9)}$ Targeted NGS was performed from the remaining 34 patients, of whom 18 had paired matched surgical pathology specimens with sufficient material for a multigene mutation concordance evaluation.

\section{DNA extraction process}

Cytology smear slides were immersed in xylene for 1-5 days until the coverslip detached. Following rinsing in 95\% ethanol, all cellular material from a single slide per patient was scraped with a sterile razor and placed into $1.5 \mathrm{ml}$ tubes. Cytology slide DNA was isolated using the QIAmp DNA Micro kit and FFPE unstained slide DNA was extracted using the QIAamp DSP DNA FFPE Tissue kit (Qiagen Inc, Valencia, CA). DNA samples were quantified using the Qubit ${ }^{\circledR}$ dsDNA BR assay kit (Life Technologies, Carlsbad, CA) as per standard protocol. Extraction yielded $21.0 \mathrm{ng} / \mu \mathrm{l}$ of DNA on average (range 0-88.7) for cytology smear specimens and $66.9 \mathrm{ng} / \mu \mathrm{l}$ of DNA (range 9.3-164) on average for FFPE specimens.

\section{Deep sequencing of multiplex PCR amplicons}

Multiplex PCR was performed by amplifying 10 ng of DNA in each of 4 separate PCR reactions using a commercial Human Comprehensive Cancer GeneRead ${ }^{\mathrm{TM}}$ DNAseq Targeted Panel V2 (Qiagen Inc, Valencia, CA) per manufacturer protocol. This panel is a collection of multiplexed PCR primer assays for targeted enrichment of the coding (exonic) regions of the 160 genes $(7,951$ amplicons) that are most frequently mutated in malignancy with an identifiable oncogenic consequence (Supplementary Table 3).

The PCR products underwent library preparation using the TruSeq Nano DNA Sample Preparation Kit (Illumina, San Diego, CA) as recommended by the manufacturer starting with the end repair reaction. For the Human Comprehensive Cancer Panel, up to 12 samples were pooled equimolar and underwent $2 \times 100 \mathrm{bp}$ sequencing on an Illumina HiSeq instrument using the 200 cycle Rapid v2 Reagent Kit (Illumina, San Diego, CA). Internal laboratory studies demonstrated 5-10\% analytical sensitivity for mutant alleles at a minimum of 100X coverage.

\section{Data analysis}

Following sequencing completion on the Illumina NGS instrument, the raw sequence reads were extracted and demultiplexed with Illumina CASAVA (Consensus Assessment of Sequence And Variation) program (version 1.8.2) to generate FASTQ files. Sequence FASTQ files were aligned to human genome build hg19 using the CLC BIO Genomics Server (version 6.0) program to produce BAM files. The alignment files were analyzed by the CLC BIO Genomics Server quality and probability variant detection program within a custom bioinformatics pipeline running on the Linux cluster. The Single nucleotide polymorphisms (SNPs) or insertions/deletions (INDELs) with an allele frequency $\geq 5 \%$ were manually reviewed and interpreted.

\section{Statistical analyses}

Continuous variables were reported as mean and standard deviation or median and interquartile range and compared by using the Student $t$ test or Mann Whitney $\mathrm{U}$ test. Categorical variables were reported as frequency (\%) and were compared by either a 2-tailed Fisher exact test or Pearson $\chi^{2}$ test, where appropriate. Progression free survival (PFS) was defined as the time from EUS FNA to any objective evidence of disease progression or death, whichever occurred first. Cox proportional hazards model was performed to estimate PFS data. All tests were 2 -sided, with $P \leq .05$ as the criterion standard for determining significance. The statistical software package JMP Version 11 (SAS Institute, Cary, NC) and MedCalc version 10 (MedCalc Software, Mariakerke, Belgium) were used for statistical analysis. 


\section{CONFLICTS OF INTEREST}

The authors have declared that no competing interests exist.

\section{FUNDING}

Biomarker Discovery, Center for Individualized Medicine, Mayo Clinic.

\section{Abbreviations}

AA: Ampullary adenocarcinoma; COSMIC: Catalogue of Somatic Mutations in Cancer; EUS FNA: Endoscopic Ultrasound Fine Needle Aspiration; FFPE: Formalin fixed paraffin embedded; IPMN: Intraductal Papillary Mucinous Neoplasm; NCI: National Cancer Institute; NGS: Next generation sequencing; PDAC: Pancreatic ductal adenocarcinoma; ROSE: Rapid on site evaluation; WT: Wild type (no somatic mutation detected).

\section{Author contribution}

\section{REFERENCES}

1. Heestand GM, Kurzrock R. Molecular landscape of pancreatic cancer: implications for current clinical trials. Oncotarget. 2015; 6:4553-61. doi: 10.18632/ oncotarget.2972.

2. http://deainfo.nci.nih.gov/advisory/ctac/workgroup/pc/ PDACframework.pdf.

3. Lowery MA, O'Reilly EM. Novel Therapeutics for Pancreatic Adenocarcinoma. Hematol Oncol Clin North Am. 2015; 29:777-87.

4. Kleger A, Perkhofer L, Seufferlein T. Smarter drugs emerging in pancreatic cancer therapy. Ann Oncol. 2014; 25:1260-70.

5. Neuzillet C, Tijeras-Raballand A, Bourget P, Cros J, Couvelard A, Sauvanet A, Vullierme MP, Tournigand C, Hammel P. State of the art and future directions of pancreatic ductal adenocarcinoma therapy. Pharmacol Ther. 2015; 155:80-104.

6. Morran DC, Wu J, Jamieson NB, Mrowinska A, Kalna G, Karim SA, Au AY, Scarlett CJ, Chang DK, Pajak MZ; Australian Pancreatic Cancer Genome Initiative (APGI), Oien KA, McKay CJ, et al. Targeting mTOR dependency in pancreatic cancer. Gut. 2014; 63:1481-9.

\begin{tabular}{|c|c|c|c|c|c|c|c|}
\hline Author & $\begin{array}{l}\text { Study } \\
\text { concept } \\
\text { and } \\
\text { design }\end{array}$ & $\begin{array}{l}\text { Acquisition } \\
\text { of data }\end{array}$ & $\begin{array}{l}\text { Analysis and } \\
\text { interpretation } \\
\text { of data }\end{array}$ & $\begin{array}{c}\text { Drafting } \\
\text { of the } \\
\text { manuscript }\end{array}$ & $\begin{array}{l}\text { Critical revision } \\
\text { of the manuscript } \\
\text { for important } \\
\text { intellectual content }\end{array}$ & $\begin{array}{c}\text { Statistical } \\
\text { analysis }\end{array}$ & $\begin{array}{c}\text { Obtained } \\
\text { funding }\end{array}$ \\
\hline $\begin{array}{l}\text { Ferga C. } \\
\text { Gleeson }\end{array}$ & $\mathbf{x}$ & $\mathbf{x}$ & $\mathbf{x}$ & $\mathbf{x}$ & $\mathbf{x}$ & $\mathbf{x}$ & $\mathbf{x}$ \\
\hline $\begin{array}{l}\text { Benjamin R. } \\
\text { Kipp }\end{array}$ & $\mathbf{x}$ & $\mathbf{x}$ & $\mathbf{x}$ & $\mathbf{x}$ & $\mathbf{x}$ & & \\
\hline Jesse S. Voss & & $\mathbf{x}$ & $\mathbf{x}$ & & $\mathbf{x}$ & & \\
\hline $\begin{array}{l}\text { Douglas M. } \\
\text { Minot }\end{array}$ & & $\mathbf{x}$ & $\mathbf{x}$ & & $\mathbf{x}$ & & \\
\hline Zheng Jin Tu & & $\mathbf{x}$ & $\mathbf{x}$ & & $\mathbf{x}$ & & \\
\hline Sarah E. Kerr & $\mathbf{x}$ & $\mathbf{x}$ & $\mathbf{x}$ & $\mathbf{x}$ & $\mathbf{x}$ & & \\
\hline $\begin{array}{l}\text { Michael R. } \\
\text { Henry }\end{array}$ & & & & & $\mathbf{x}$ & & \\
\hline $\begin{array}{l}\text { Rondell P. } \\
\text { Graham }\end{array}$ & & $\mathbf{x}$ & & & $\mathbf{x}$ & & \\
\hline $\begin{array}{l}\text { George } \\
\text { Vasmatzis }\end{array}$ & & & & & $\mathbf{x}$ & & \\
\hline $\begin{array}{l}\text { John C. } \\
\text { Cheville }\end{array}$ & & & & & $\mathbf{x}$ & & \\
\hline $\begin{array}{l}\text { Konstantinos } \\
\text { N. Lazaridis }\end{array}$ & & & & & $\mathbf{x}$ & & \\
\hline Michael J. Levy & $\mathbf{x}$ & $\mathbf{x}$ & & $\mathbf{x}$ & $\mathbf{x}$ & & $\mathbf{x}$ \\
\hline
\end{tabular}


7. Iacobuzio-Donahue CA, Fu B, Yachida S, Luo M, Abe H, Henderson CM, Vilardell F, Wang Z, Keller JW, Banerjee P, Herman JM, Cameron JL, Yeo CJ, et al. DDPC4 gene status of the primary carcinoma correlates with patterns of failure in patients with pancreatic cancer. Journal of clinical oncology. 2009; 27:1806.

8. Iacobuzio-Donahue CA, Herman JM. Autophagy, p53, and pancreatic cancer. N Engl J Med. 2014; 370:1352-3.

9. Gleeson FC, Kipp BR, Levy MJ, Voss JS, Campion MB, Minot DM, Tu ZJ, Klee EW, Lazaridis KN, Kerr SE. Lung cancer adrenal gland metastasis: Optimal fineneedle aspirate and touch preparation smear cellularity characteristics for successful theranostic next-generation sequencing. Cancer Cytopathol. 2014; 122:822-32. doi: 10.1002/cncy.21464.

10. Jones S, Zhang X, Parsons DW, Lin JC, Leary RJ, Angenendt P, Mankoo P, Carter H, Kamiyama H, Jimeno A, Hong SM, Fu B, Lin MT, et al. Core signaling pathways in human pancreatic cancers revealed by global genomic analyses. Science. 2008; 321:1801-1806.

11. Biankin AV, Waddell N, Kassahn KS, Gingras MC, Muthuswamy LB, Johns AL, Miller DK, Wilson PJ, Patch AM, Wu J, Chang DK, Cowley MJ, Gardiner BB, et al. Pancreatic cancer genomes reveal aberrations in axon guidance pathway genes. Nature. 2012; 491:399-405.

12. Gleeson FC, Kipp BR, Voss JS, Campion MB, Minot DM, Tu ZJ, Klee EW, Sciallis AP, Graham RP, Lazaridis KN, Henry MR, Levy MJ. Endoscopic ultrasound fine-needle aspiration cytology mutation profiling using targeted nextgeneration sequencing: personalized care for rectal cancer. Am J Clin Pathol. 2015; 143:879-88.

13. Gleeson FC, Kipp BR, Voss JS, Campion MB, Minot DM, Tu ZJ, Klee EW, Graham RP, Lazaridis KN, Henry MR, Levy MJ. Frequency of mitogen-activated protein kinase and phosphoinositide 3-kinase signaling pathway pathogenic alterations in EUS-FNA sampled malignant lymph nodes in rectal cancer with theranostic potential. Gastrointest Endosc. 2015; 82:550-6.

14. Gleeson FC, Kipp BR, Levy MJ, Voss JS, Campion MB, Minot DM, Tu ZJ, Klee EW, Lazaridis KN, Kerr SE. Somatic STK11 and concomitant STK11/KRAS mutational frequency in stage IV lung adenocarcinoma adrenal metastases. J Thorac Oncol. 2015; 10:531-4.

15. Gleeson FC, Kipp BR, Kerr SE, Voss JS, Lazaridis KN, Katzka DA, Levy MJ. Characterization of endoscopic ultrasound fine-needle aspiration cytology by targeted next-generation sequencing and theranostic potential. Clin Gastroenterol Hepatol. 2015; 13:37-41.

16. Gleeson FC, Kipp BR, Kerr SE, Voss JS, Graham RP, Campion MB, Minot DM, Tu ZJ, Klee EW, Lazaridis KN, Henry MR, Levy MJ. Kinase genotype analysis of gastric gastrointestinal stromal tumor cytology samples using targeted next-generation sequencing. Clin Gastroenterol Hepatol. 2015; 13:202-6.
17. Knudsen ES, O'Reilly EM, Brody JR, Witkiewicz AK. Genetic Diversity of Pancreatic Ductal Adenocarcinoma and Opportunities for Precision Medicine. Gastroenterology. 2016; 150:48-63.

18. Ogura T, Yamao K, Sawaki A, Mizuno N, Hara K, Hijioka S, Niwa Y, Tajika M, Kondo S, Shimizu Y, Bhatia V, Higuchi K, Hosoda W, et al. Clinical impact of K-ras mutation analysis in EUS-guided FNA specimens from pancreatic masses. Gastrointest Endosc. 2012; 75:769-74.

19. Fuccio L, Hassan C, Laterza L, Correale L, Pagano N, Bocus P, Fabbri C, Maimone A, Cennamo V, Repici A, Costamagna G, Bazzoli F, Larghi A. The role of K-ras gene mutation analysis in EUS-guided FNA cytology specimens for the differential diagnosis of pancreatic solid masses: a meta-analysis of prospective studies. Gastrointest Endosc. 2013; 78:596-608.

20. Bournet B, Souque A, Senesse P, Assenat E, Barthet M, Lesavre N, Aubert A, O'Toole D, Hammel P, Levy P, Ruszniewski P, Bouisson M, Escourrou J, et al. Endoscopic ultrasound-guided fine-needle aspiration biopsy coupled with KRAS mutation assay to distinguish pancreatic cancer from pseudotumoral chronic pancreatitis. Endoscopy. 2009; 41:552-7.

21. Bournet B, Selves J, Grand D, Danjoux M, Hanoun N, Cordelier P, Buscail L. Endoscopic ultrasound-guided fineneedle aspiration biopsy coupled with a KRAS mutation assay using allelic discrimination improves the diagnosis of pancreatic cancer. J Clin Gastroenterol. 2015; 49:50-6.

22. Maluf-Filho F, Kumar A, Gerhardt R, Kubrusly M, Sakai P, Hondo F, Matuguma SE, Artifon E, Monteiro da Cunha JE, César Machado MC, Ishioka S, Forero E. Kras mutation analysis of fine needle aspirate under EUS guidance facilitates risk stratification of patients with pancreatic mass. J Clin Gastroenterol. 2007; 41:906-10.

23. Valero V 3rd, Saunders TJ, He J, Weiss MJ, Cameron JL, Dholakia A, Wild AT, Shin EJ, Khashab MA, O'BroinLennon AM, Ali SZ, Laheru D, Hruban RH, et al. Reliable Detection of Somatic Mutations in Fine Needle Aspirates of Pancreatic Cancer with Next-generation Sequencing: Implications for Surgical Management. Ann Surg. 2016; 263:153-61.

24. Prickett TD, Zerlanko BJ, Hill VK, Gartner JJ, Qutob N, Jiang J, Simaan M, Wunderlich J, Gutkind JS, Rosenberg SA, Samuels Y. Somatic mutation of GRIN2A in malignant melanoma results in loss of tumor suppressor activity via aberrant NMDAR complex formation. J Invest Dermatol. 2014; 134:2390-8.

25. Miettinen M, McCue PA, Sarlomo-Rikala M, Rys J, Czapiewski P, Wazny K, Langfort R, Waloszczyk P, Biernat W, Lasota J, Wang Z. GATA3: a multispecific but potentially useful marker in surgical pathology: a systematic analysis of 2500 epithelial and nonepithelial tumors. Am J Surg Pathol. 2014; 38:13-22. 
26. Waddell N, Pajic M, Patch AM, Chang DK, Kassahn KS, Bailey P, Johns AL, Miller D, Nones K, Quek K, Quinn $\mathrm{MC}$, Robertson AJ, Fadlullah MZ, et al. Whole genomes redefine the mutational landscape of pancreatic cancer. Nature. 2015; 518:495-501.

27. Feig C, Gopinathan A, Neesse A, Chan DS, Cook N, Tuveson DA. The pancreas cancer microenvironment. Clin Cancer Res. 2012; 18:4266-76.
28. Neesse A, Algül H, Tuveson DA, Gress TM. Stromal biology and therapy in pancreatic cancer: a changing paradigm. Gut. 2015; 64:1476-84. 